\title{
Radius-Lunate Joint
}

National Cancer Institute

\section{Source}

National Cancer Institute. Radius-Lunate Joint. NCI Thesaurus. Code C142310.

The articulation of the radius and the lunate bone in the wrist. 